\title{
Kajian Proses Pemarutan Empulur Sagu Menggunakan Alat Parut Sagu Bertenaga Manual dan Motor Bakar
}

\section{Study Of Sago Rasping Process Using Manual And Cobustion Engine Powered of Sago Rasping Tool}

\author{
Reniana $^{1 *}$, Darma ${ }^{1}$ dan Aceng Kurniawan ${ }^{2}$ \\ ${ }^{1}$ Jurusan Teknik Pertanian dan Biosistem, Universitas Papua \\ Jl. Gunung Salju Amban, Manokwari 98314. \\ ${ }^{2}$ Jurusan Teknologi Hasil Pertanian, Universitas Papua \\ Jl. Gunung Salju Amban, Manokwari 98314. \\ *Email: ana.iner@gmail.com
}

\begin{abstract}
In principle, the traditional processing of sago includes felling, cutting, splitting, crushing pith, squeezing, filtering, depositing and packaging. The initial stage in the sago processing process that requires the most time and effort is the process of crushing the pith. Therefore, in order to solve this problem, the design of a manual pawered sago rasp and a combustion engine are needed. In addition, studies related to the process of rasping pith using a sago rasped machine are important so that the performance and operation method can be ascertained. The results showed that the operation of manual and motor-fueled sago grater was quite simple, where the grating capacity was $69.46 \mathrm{~kg} / \mathrm{hour}$ and $322.52 \mathrm{~kg} / \mathrm{hour}$, starch yield $34.74 \%$ and $37.44 \%$ and evaluation of starch in dregs $5.67 \%$ and $2.34 \%$ of the use of the respective tools.
\end{abstract}

Keywords: sago starch, rasp, manual, combustion engine

\begin{abstract}
Abstrak
Proses pengolahan sagu secara tradisional pada prinsipnya meliputi penebangan, pemotongan, pembelahan, penghancuran empulur, pemerasan, penyaringan, pengendapan dan pengemasan. Tahapan awal pada proses pengolahan sagu yang paling banyak membutuhkan waktu dan tenaga yaitu pada proses penghancuran empulur. Oleh sebab itu, untuk mengatasi masalah tersebut maka sebuah perancangan suatu alat parut sagu bertenaga manual dan motor bakar sangat diperlukan. Selain itu, studi terkait proses pemarutan empulur menggunakan mesin parut sagu tersebut merupakan hal yang penting sehingga dapat diketahui kinerja serta cara pengoperasiannya secara pasti. Hasil penelitian menunjukkan bahwa pengoperasian alat parut sagu bertenaga manual dan motor bakar cukup mudah dimana diperoleh kapasitas pemarutan $69,46 \mathrm{~kg} / \mathrm{jam}$ dan $322,52 \mathrm{~kg} / \mathrm{jam}$, rendemen pati $34,74 \%$ dan $37,44 \%$ dan evaluasi pati dalam ampas $5,67 \%$ dan 2,34\% dari penggunaan masing-masing alat.
\end{abstract}

Kata kunci : pati sagu, parut, manual, motor bakar

\section{PENDAHULUAN}

Sekitar $90 \%$ atau 1.015 juta ha tanaman sagu berkembang di Papua dan Maluku, dimana sekitar $40 \%$ dari jumlah tegakan sagu (seluas 300.000 ha) yang tumbuh di Papua merupakan tanaman produktif yang siap panen, namun baru dimanfaatkan sekitar
$0.34 \%$ atau sekitar 7.140 ton/tahun) (Limbongan, 2007). Di Papua, sagu mempunyai peranan sosial, ekonomi, dan budaya yang cukup penting, karena merupakan bahan makanan pokok bagi masyarakat terutama yang bermukim di daerah pesisir (Kanro, dkk. 2003). Selain digunakan sebagai makanan pokok, makanan tambahan dan 
makanan ternak, sagu juga digunakan sebagai bahan baku industri pangan, farmasi, tekstil, pestisida dan lain-lain (Haryanto dan Pangloli, 1992).

Namum kenyataannya potensi areal sagu tersebut belum dieksploitasi secara maksimal sebagai penghasil pati sagu untuk kebutuhan lokal (pangan) maupun untuk komoditi eksport (Samad, 1996). Menurut BPBPI (2007), potensi produksi sagu di Indonesia diperkirakan 5 juta ton pati sagu kering/tahun, namun realisasi pemanfaatannya masih sangat rendah yaitu sekitar 210 ribu ton/tahun atau sekitar $4-5 \%$ dari potensi yang ada. Bintoro (2011) memperkirakan potensi sagu di Indonesia berkisar $20-40$ ton pati/ha/tahun.

Rendahnya produksi pati sagu di Papua saat ini disebabkan beberapa faktor utama yakni lokasi areal sagu yang umumnya di daerah marginal dengan kondisi geografi dan demografi yang tidak menunjang serta sarana produksi yang relatif tradisional (Samad, 1996). Proses pengolahan sagu secara tradisional pada prinsipnya meliputi penebangan, pemotongan, pembelahan, penghancuran empulur, pemerasan, penyaringan, pengendapan dan pengemasan. Tahapan awal pada proses pengolahan sagu yang paling banyak membutuhkan waktu dan menguras banyak tenaga adalah pada proses penghancuran empulur. Secara tradisional, penghancuran empulur sagu dilakukan dengan menggunakan tokok dengan prinsip kerja menumbuk dan menggaruk empulur sagu sehingga ukurannya menjadi lebih kecil untuk mempermudah porses ekstraksi pati sagu. Menurut Haryanto dan Pangloli (1992), kapasitas kerja rata-rata 2 orang hanya dapat menokok 2,5 meter/hari, sedangkan menurut Samad (2007), dibutuhkan 4 orang untuk mengolah 2 batang sagu selama 6 hari.

Untuk mengatasi masalah tersebut maka perlu dilakukan pembenahan terhadap keterbatasan kemampuan masyarakat dalam memproduksi pati sagu. Salah satu cara yang dapat dilakukan adalah dengan memperbaiki teknik pengolahan yang digunakan pada semua tahapan pengolahan sagu, terutama pada proses penghancuran empulur, karena pada tahapan ini banyak membutuhkan tenaga kerja serta menguras tenaga. Secara tradisional penghancuran empulur dilakukan dengan menggunakan tokok, suatu alat sejenis palu yang prinsip kerjanya mengkombinasikan gerakan menumbuk dan menggaruk yang mengakibatkan jaringan terpotong-potong menjadi ukuran kecil sehingga partikel pati terlepas. Penghancuran empulur dapat dilakukan dengan pemarutan sebagaimana telah banyak dilakukan di beberapa daerah tertentu.

Di beberapa daerah termasuk di Papua, penghancuran empulur sagu sudah dilakukan dengan alat parut mekanis bertenaga diesel, namun pada umumnya alat parut tersebut menggunakan daya/tenaga yang tinggi dan kontruksinya besar sehingga susah untuk dipindah-pindahkan. Mengingat areal tanaman sagu di Papua letaknya jauh dari pemukiman penduduk, dan daerahnya sukar dijangkau, maka perancangan suatu alat parut sagu bertenaga manual dan motor bakar sangat diperlukan. Selain itu, studi berkaitan dengan proses pemarutan empulur menggunakan mesin parut sagu tersebut merupakan hal yang penting sehingga dpat diketahui kinerja cara pengoperasiannya secara pasti. Menurut Arora (2004), agar suatu sistem/alat dapat diterima, maka system/alat tersebut harus bersifat hemat biaya (cost), efektif (effective), tepat guna (efficient), dapat dipercaya (reliable), dan tahan lama (durable). Tujuan dari penelitian ini adalah untuk mengkaji proses pengoperasian alat parut empulur sagu bertenaga manual dan motor bakar sehingga dapat diketahui kinerja terbaik serta cara pengoperasiannya.

\section{BAHAN DAN METODE}

\section{Bahan dan Alat}

Bahan yang digunakan dalam penelitian ini yaitu empulur batang sagu sebagai bahan untuk diparut, bensin, dan air. Sedangkan peralatan yang digunakan yaitu alat parut sagu bertenaga manual dan alat parut sagu bertenaga motor bakar, timbangan, stopwatch, ember, saringan, gelas ukur, tachometer, chain saw, parang, dan kampak.

\section{Metode Penelitian}

Tahapan penelitian ini terbagi menjadi dua yaitu penyiapan empulur sagu dan pengujian alat. Tahap penyiapan emupulur sagu meliputi pemilihan pohon sagu siap panen, penebangan, pemotongan batang sagu, pengupasan kulit batang sagu dan pembelahan 
menjadi ukuran yang siap untuk diparut. Tahap pengujian dilakukan dengan memarut empulur batang sagu menggunakan alat parut sagu bertenaga manual dan motor bakar. Adapun variabel yang diamati meliputi kapasitas pemarutan, rendemen pati dan kadar pati dalam ampas.

\section{Kapasitas Pemarutan}

Dengan menimbang langsung hasil parutan empulur sagu (Me) dan menghitung waktu yang diberikan (t), perhitungan kapasitas pemarutan (KP) dituliskan dengan persamaan 1.

$$
\mathrm{KP}=\frac{M e(\mathrm{~kg})}{t(j a m)}
$$

\section{Rendemen Pati}

Hasil parutan empulur sagu ditimbang massanya (Me), kemudian diemulsikan dengan air dan diperas berkali-kali diatas saringan untuk diambil patinya (proses ekstraksi pati sagu). Hasil perasan didiamkan beberapa saat hingga butiran pati mengendap. Pati diambil dan ditimbang massanya (Mp). Perhitungan rendemen pati ( $\mathrm{Rd})$ dituliskan dengan persamaan 2:

$$
\mathrm{Rd}=\frac{M p(k g)}{M e(k g)} \times 100 \%
$$

\section{Evaluasi pati dalam ampas}

Untuk menilai kualitas hasil parutan, ampas hasil ekstraksi ditimbang massanya (Mea) lalu ditumbuk dan diemulsikan kembali dengan air, kemudian diperas berkali-kali sampai air perasan jernih. Pati hasil perasan ulang ini ditimbang (Mpa), perhitungan kualitas hasil parutan dituliskan dengan persamaan 3:

$$
\mathrm{Ra}=\frac{M p a(\mathrm{~kg})}{M e a(\mathrm{~kg})} \times 100 \%
$$

\section{HASIL DAN PEMBAHASAN}

\section{Kontruksi Alat Parut Sagu Bertenaga Manual dan Motor Bakar}

Kedua alat parut sagu ini secara umum terdiri dari lima bagian utama yaitu rangka utama (frame), sumber penggerak, sistem transmisi daya, mekanisme pengumpan, dan silinder pemarut. Perbedaan kontruksi terletak pada sumber penggerak dan sistem transmisi daya yang digunakan. Pada alat parut sagu bertenaga manual (Gambar 1a), sumber penggerak menggunakan pedal dengan sistem transmisi sprocket dan rantai. Prinsip kerja dari alat ini yaitu pedal digerakan oleh injakan kaki operator sehingga dapat menggerakkan silinder pemarut. Dengan bantuan pegas yang terpasang pada rantai dan pedal akan menghasilkan gerakan translasi naik turun, gerakan ini diubah menjadi putaran oleh sprocket yang terpasang pada poros silinder pemarut. Dengan berputarnya silinder pemarut maka empulur sagu yang diumpankan dapat terparut. Sedangkan pada alat parut sagu bertenaga motor bakar (Gambar 1b), sumber penggerak menggunakan motor bakar bensin 5.5 HP dengan sistem transmisi daya pulley dan V-belt.

Sistem kerjanya yaitu gerakan atau putaran yang dihasilkan oleh mesin disalurkan melalui sistem transmisi pulley dan V-belt sehingga dapat memutar silinder pemarut dan memarut empulur sagu yang diumpankan. Pengoperasian alat ini sangat sederhana yaitu dengan mengumpankan empulur batang sagu melalui saluran pengumpan sehingga empulur batang sagu dapat terparut oleh silinder pemarut yang berputar. Proses ini dilakukan secara hati-hati dimana apabila empulur batang sagu yang sudah terparut tersisa kurang lebih $20 \mathrm{~cm}$ maka harus segera didorong dengan empulur sagu yang baru.

Hal ini dilakukan agar terhindar dari cedera/kecelakaan kerja seperti tangan atau jari terkena gigi yang terpasang pada silinder pemarut yang berputar. Secara umum kontruksi dan cara pengoperasian dari kedua alat tersebut ditampilkan pada Gambar 1 dan 2. 


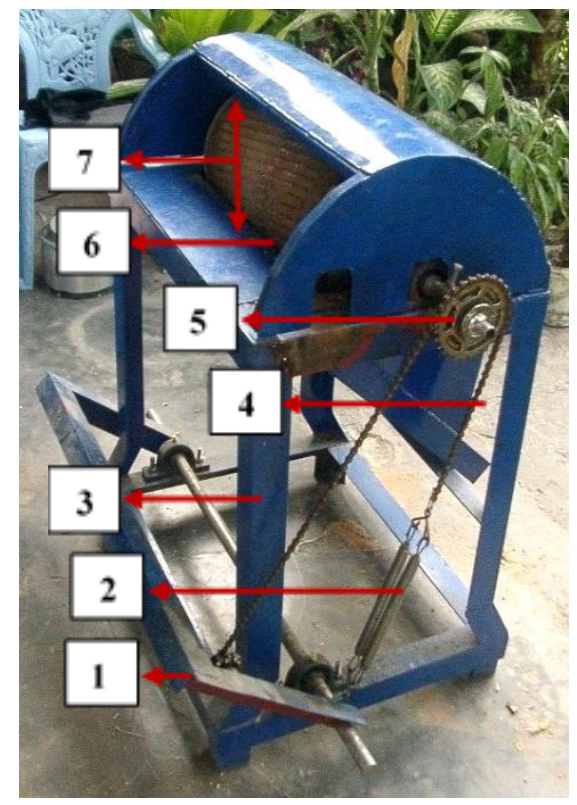

(a).

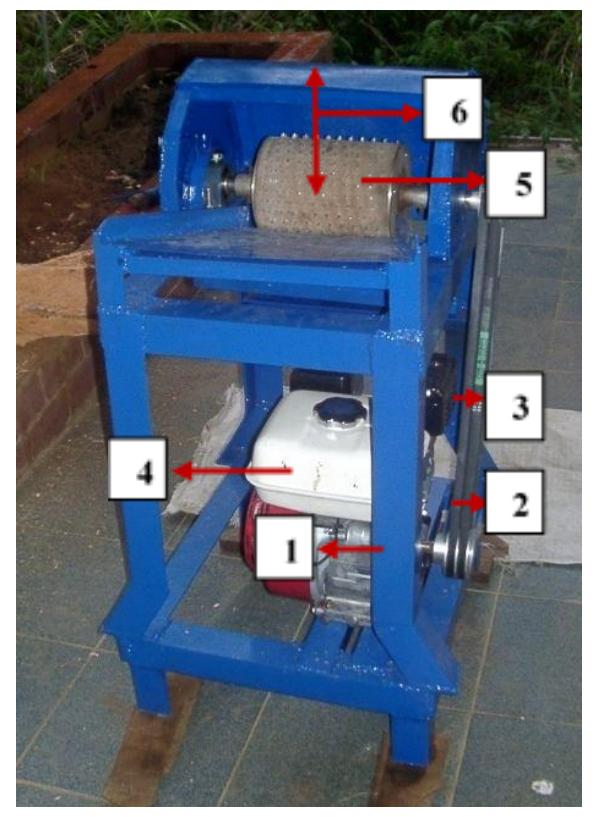

(b).

Gambar 1. Kontruksi mesin parut sagu bertenaga manual (a) ; 1. Pedal, 2. Pegas, 3. Rangka, 4. Rantai, 5. Sprocket, 6. Silinder pemarut, dan 7. Saluran pengumpan. Kontruksi mesin parut sagu bertenaga motor bakar (b) ; 1. Rangka utama, 2. Pulley, 3. V-belt, 4. Motor bakar, 5. Silinder pemarut, dan 6. Saluran masuk.

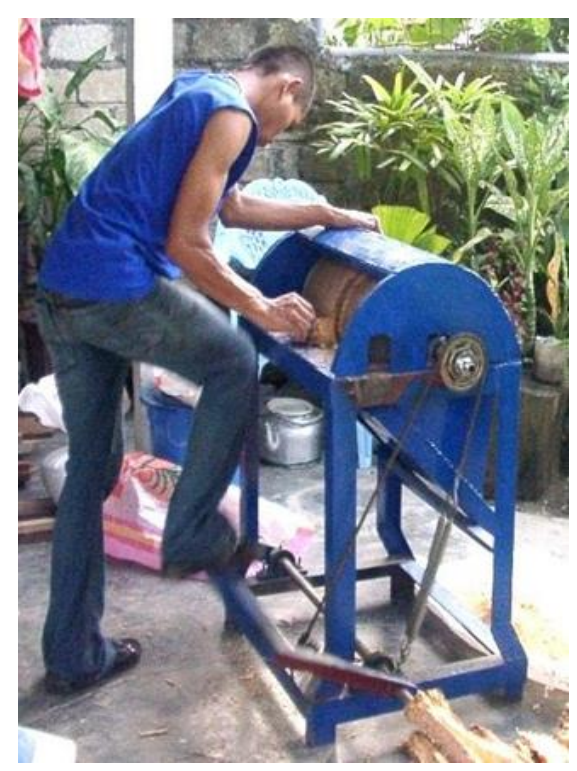

(a).

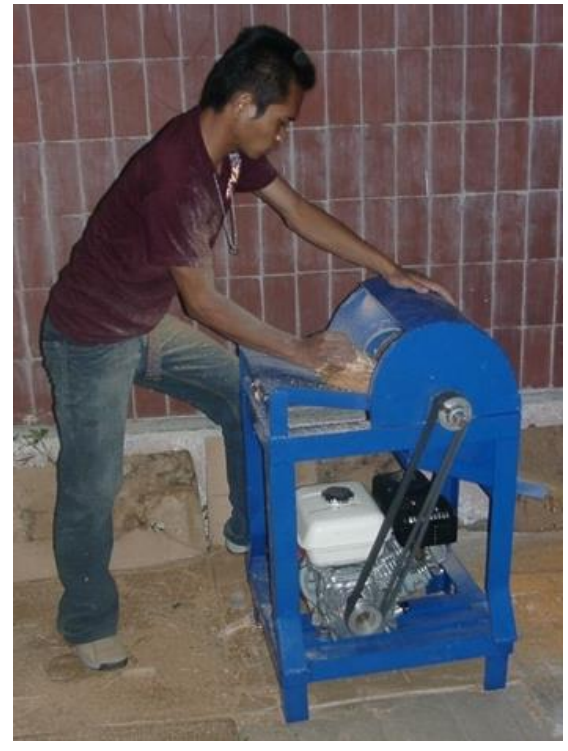

(b).

Gambar 2. Cara pengoperaian alat parut sagu bertenaga manual (a) dan motor bakar (b). 


\section{Kapasitas Pemarutan, Rendeman Pati dan Kadar Pati dalam Ampas}

Pemarutan merupakan proses memperkecil ukuran bahan (merusak dinding sel) agar pati yang terdapat dalam sel dapat keluar pada proses lebih lanjut. Kapasitas pemarutan merupakan kemampuan mesin parut sagu dalam memarut empulur persatuan waktu. Rendemen pati adalah kandungan pati yang terdapat dalam empulur sagu yang telah diekstraksi. Sedangkan evaluasi pati dalam ampas merupakan tolok ukur dari kualitas hasil parutan. Berdasarkan hasil penelitian, diperoleh kapasitas pemarutan, rendemen pati dan kadar pati dalam ampas dari pengujian kedua alat parut sagu ditampilkan dalam Tabel 1 .

Tabel 1. Kapasitas pemarutan, rendemen pati dan evaluasi pati dalam ampas dari hasil pengujian alat parut sagu bertenaga manual dan motor bakar.

\begin{tabular}{lccc}
\hline \multicolumn{1}{c}{ Alat Parut Sagu } & $\begin{array}{c}\text { Kapasitas Pemarutan } \\
\text { (kg/jam) }\end{array}$ & Rendemen Pati (\%) & $\begin{array}{c}\text { Evaluasi pati } \\
\text { dalam Ampas (\%) }\end{array}$ \\
\hline Bertenaga manual & 69,49 & 34,74 & 5,67 \\
Bertenaga motor bakar & 322,52 & 37,44 & 2.34 \\
\hline
\end{tabular}

Berdasarkan pengujian kedua alat parut sagu, diperoleh kapasitas pemarutan yaitu $69,46 \mathrm{~kg} / \mathrm{jam}$ dan $322,52 \mathrm{~kg} / \mathrm{jam}$ untuk masing-masing penggunaan alat parut sagu bertenaga manual dan motor bakar. Bila dibandingkan dengan penokokan secara tradisional, kapasitas pemarutan kedua alat parut sagu jauh lebih tinggi, terutama dengan menggunakan penggerak motor bakar. Secara tradisional, kapasitas kerja rata-rata 2 orang hanya dapat menokok 2.5 meter/hari dengan berat rata-rata $65,23 \mathrm{~kg}$ empulur/meter atau setara 10,19 kg/jam/orang (Haryanto dan Pangloli, 1992). Tinggi rendahnya kapasitas pemarutan kedua alat parut sagu dipengaruhi oleh sumber penggerak yang digunakan. Pada alat parut sagu bertenaga manual, sumber penggerak yang digunakan yaitu tenaga manusia berupa injakan kaki pada pedal oleh operator yang memarut sagu sehingga putaran silinder pemarut yang dihasilkan relatif rendah yaitu sekitar 512 rpm. Bila dibandingkan dengan alat parut bertenaga motor bakar dapat menghasilkan putaran silinder pemarut mencapai $3500 \mathrm{rpm}$.

Berdasarkan hasil penelitian, besarnya putaran silinder pemarut sejalan dengan tingginya kapasitas pemarutan, dimana semakin tinggi putaran silinder pemarut maka proses pemarutan berlangsung cepat dan semakin tinggi kapasitas pemarutannya. Harling (2017) melaporkan perbandingan kapasitas produksi pemarutan secara tradisional dan menggunakan alat parut bertenaga listrik yaitu $57,29 \mathrm{~kg} / \mathrm{jam}$ dan 132,6 $\mathrm{kg} / \mathrm{jam}$. Rizalinoor (2019) melaporkan kapasitas pemarutan dari alat pemarut sagu portable rancangannya adalah $250 \mathrm{~kg} / \mathrm{jam}$. Sedangkan Darma dan Triyanto (2015); Indra dan Susanto (2016) dan Toriq dan Sutejo (2017), melaporkan kapasitas pemarutan dari masing-masing alat pemarut empulur sagu bertenaga motor bakar berturut-turut yaitu 627 $\mathrm{kg} / \mathrm{jam}, 600 \mathrm{~kg} / \mathrm{jam}$ dan 649,38 kg/jam.

Rendemen pati yang diperoleh pada penelitian ini cukup tinggi yaitu $34,74 \%$ dan $37,44 \%$ untuk masing-masing penggunaan alat parut sagu bertenaga manual dan motor bakar. Perbedaan rendemen pati dari penggunaan kedua alat parut sagu tersebut dipengaruhi oleh ukuran empulur hasil pemarutan (ella). Dalam penelitian ini, kerapatan bahan (empulur) dengan silinder pemarut selama proses pemarutan mempengaruhi ukuran ella hasil pemarutan. Semakin rapat bahan (empulur sagu) dengan silinder parut maka akan menghasilkan serat hasil parutan yang kecil. Kecepatan putar silinder pemarut diduga sangat mempengaruhi hasil tersebut. Pada alat parut bertenaga manual, karena putaran silinder parut rendah dan hanya menggunakan tenaga manusia maka dalam memarut empulur sagu diberikan dorongan pelan menyesuaikan kekuatan injakan pedal oleh operator. Oleh karenanya akan memberikan jarak kerapatan empulur sagu dengan silinder pemarut sehingga dihasilkan ella hasil parutan yang lebih besar.

Berbeda dengan alat parut bertenaga motor bakar, karena putaran silinder pemarutnya tinggi dan berasal dari tenaga motor bakar maka dalam pengoperasiannya, bahan diberikan dorongan penuh sehingga semakin rapat jarak antara bahan dengan 
silinder pemarut yang berdampak pada ukuran ella hasil pemarutan lebih kecil-kecil bila dibandingkan dengan alat parut bertenaga manual. Tujuan pemarutan yaitu untuk merusak dinding sel dari empulur sagu, karena butiran pati terdapat didalam sel (sel empulur sagu), semakin halus hasil parutan empulur sagu maka semakin banyak sel yang rusak dan semakin banyak pula pati terekstrak. Menurut Zainudin dan Ngudiwaluyo (1996), pemarutan merupakan bagian dari proses pengolahan yang berperan sebagai pengubah potonganpotongan batang sagu menjadi serat-serat, semakin kecil serat hasil parutan maka makin mudah pati dilepaskan. Hal tersebut dipengaruhi oleh luas bidang bahan yang akan diparut, jari-jari silinder, alat parut, jumlah dan ukuran gigi parut, kecepatan putaran parut serta kerapatan bahan yang akan diparut. Selain itu, tingginya rendemen pati pada penelitian ini dikarenakan pohon sagu yang diolah termasuk jenis sagu dengan kadar pati tinggi dan merupakan massa panennya. Haryanto dan Pangloli (1992); Flach (1997), melaporkan rata-rata kandungan pati sagu dalam empulur pada umur panen sekitar 15 $25 \%$ dan $10-25 \%$. Juga dilaporkan bahwa tinggi rendahnya rendemen pati sagu dipengaruhi oleh umur, jenis dan tempat tumbuh sagu. Selain itu, teknik pengolahan yang dilakukan juga merupakan salah satu faktor penentu tinggi rendahnya rendemen pati yang dihasilkan (Darma, 2006). Hermanto, dkk (2011), melaporkan dengan menggunakan berbagai jenis mata parut dihasilkan rendemen pati yang berdeda nyata yaitu berkisar antara $19,31 \%-24,34 \%$.

Kualitas hasil parutan yang dihasilkan pada penelitian ini termasuk tinggi. Hal ini ditunjukkan oleh kadar pati yang terikut ke ampas yaitu 5,67\% dan 2,34\% dari masingmasing penggunaan alat parut bertenaga manual dan motor bakar. Tinggi rendahnya kadar pati dalam ampas dipengaruhi oleh kehalusan serat hasil pemarutan, semakin halus serat maka semakin banyak pati yang terekstrak sehingga semakin sedikit pati yang terikut dalam ampas. Soehardiyanto (1981), melaporkan bahwa kadar pati yang terikut kedalam ampas berkisar antara 5,3-5,7\% dengan menggunakan alat parut dan penyaring bertenaga diesel. Sedangkan Purmiyanti dkk (2013), melaporkan dengan menggunakan alat yang terdiri atas 3 buah unit operasi yaitu pemarutan, ekstraksi dan pengendapan diperoleh kehilangan hasil antara 2,4-3,2\%. Sedangkan Darma (2006) melaporkan kadar pati yang masih terikut ke ampas hasil pengolahan secara manual yang dilakukan oleh masyarakat Papua sebesar 9,3\%

\section{KESIMPULAN}

Dari hasil penelitian, pengoperasian menggunakan alat parut sagu bertenaga manual dan motor bakar cukup mudah dimana kinerjanya diperoleh kapasitas pemarutan $69,46 \mathrm{~kg} / \mathrm{jam}$ dan $322,52 \mathrm{~kg} / \mathrm{jam}$, rendemen pati $34,74 \%$ dan $37,44 \%$ dan evaluasi pati dalam ampas 5,67 \% dan 2,34\% dari penggunaan masing-masing alat.

\section{DAFTAR PUSTAKA}

Arora, J. S. 2004. Introduction to Optimum Design. McGraw-Hill Book Company, 2nd Ed. New York, pp $1-12$.

Bintoro, M. H. 2011. Progress of Sago Research in Indonesia. In Proc. 10th Int.Sago Symposium: Sago for food security, Bio-energy, and Industry From Research to Market, 16-34, Bogor, 2931 October.

BPBPI, 2007. Tanaman Sagu Sebagai Sumber Energi Alternatif. Balai Penelitian Bioteknologi Perkebunan Indonesia. Warta Penelitian dan Pengembangan Pertanian Vol.29, No.4.

Darma (2006). Small Scale Processing of Sago: An Alternative Solution to Optimize Sago Resources Utilization in Papua. Dalam : Sago Palm Development and Utilization. Proceeding of 8th International Sago Symposium. Universitas Negeri Papua, Manokwari.

Darma dan Budi Triyanto. 2015. Pengembangan dan Uji Performansi Alat Pemarut Sagu Tipe Silinder Bertenaga Motor Bakar, dalam : Energi Alternatif dan Terbarukan (EAT) Prosiding Seminar Nasional Perteta 2015 Makassar, 5-7 Agustus 2015.

Flach, M. 1997. Sago Palm Metroxylon Sagu Rott. International Plant Genetic Resources Intitute (IPGRI). Rome. 
Harling, V. N. V. 2018. Analisis Perbandingan Produksi Sagu Secara Tradisional dan Modern Pada Alat Parut Sagu Dengan Menggunakan Motor Penggerak Listrik. Jurnal Soscied Vol. 1. No. 1. 2018 .

Haryanto, B. dan P. Pangloli. 1992. Potensi dan Pemanfaatan Sagu. Kanisius. Yogyakarta.

Hermanto, Ansharullah, Asrin Nuwiyah dan Muhidin. 2011. Perbedaan Teknik Pemarutan dan Pengaruhnya Terhadap Peningkatan Rendemen dan Mutu Tepung Sagu Jurnal Agriplus, Volume 21 Nomor : 01 Januari 2011.

Indra, A dan A. Susanto. 2016. Alat Pemarut Batang Sagu Portable. Jurnal Inovtek, Volume 6, Nomor 2, Oktober 2016, hlm. $73-77$.

Kanro,. M. Z, Aser Rouw, A. Widjono, Syamsuddin, Amisnaipa dan Atekan. 2003. Tanaman Sagu dan Pemanfaatannya di Papua. Balai Pengkajian Teknologi Pertanian Papua. Jurnal Litbang Pertanian.

Limbongan, J. 2007. Morfologi Berbagai Jenis Sagu Potensial di Papua. Balai Pengkajian Teknologi Pertanian Papua. Jurnal Litbang Pertanian.

Purmiyanti. S, Supriyadi, I. Inounou, Hermanto, N. Bermawie, V. R. Hermawanto, T. Sutater, Istriningsih,
K. Tresnawati, Eva Yuliana, dan T. E. Kailaku. 2013. 400 Teknologi inovatif Pertanian. Badan Penelitian dan Pengembangan Pertanian. Jakarta: IAARD Press, 2013 xv, $415 \mathrm{hlm}$.

Rizalinoor, M. 2019. Perancangan Pemarut Sagu Portable Kapasitas $250 \mathrm{Kg} / \mathrm{Jam}$. Skripsi Sarjana. Fakultas Teknik Universitas Muhammadiyah Malang.

Samad, M.Y. 1996. Sagu Dalam Kontex Pangan Nasional, dalam : Potensi Sagu Dalam Usaha Pengembangan Agribisnis di Wilayah Lahan Basah. Prosiding Symposium Nasional Sagu III. Universitas Riau. Pekanbaru.

Samad, M.Y. 2007. Meningkatkan Produksi Industri Kecil Melalui Penerapan Teknologi Ekstraksi Semi Mekanis. Pustaka IPTEK. Jurnal Saint dan Teknologi BPPT.

Toriq, A. dan A. Sutejo. 2017. Desain dan Uji Kinerja Mesin Pemarut Sagu Tipe TPB 01. Jurnal AGRITECH, Vol. 37, No. 4, November 2017, Hal. 453-461.

Zainudin, I. Dan S. Ngudiwaluyo. 1996. Pengembangan Peralatan Pengolahan Sagu (Studi Kasus Desa Peyagun Kec. Tebing Tinggi Riau), dalam : Potensi Sagu Dalam Usaha Pengembangan Agribisnis di Wilayah Lahan Basah. Prosiding Symposium Nasional Sagu III. Universitas Riau. Pekanbaru. 